\title{
Assessing Awareness, Knowledge and Use of Folic Acid in Kansas Women Between the Ages of 18 and 44 Years
}

Article in Maternal and Child Health Journal · September 2008

DOI: $10.1007 /$ s10995-008-0414-5 · Source: PubMed

CITATIONS

15

6 authors, including:

\section{Lorenda Ann Naylor}

University of Baltimore

20 PUBLICATIONS 26 CITATIONS

SEE PROFILE
READS

94

\section{Pradeep Chandra}

CVR College of Engineering 2 PUBLICATIONS 18 CITATIONS

SEE PROFILE 


\title{
Assessing Awareness, Knowledge and Use of Folic Acid in Kansas Women Between the Ages of 18 and 44 Years
}

\author{
Glynda F. Sharp · Lorenda A. Naylor • \\ Jinwen Cai - Melissa L. Hyder · Pradeep Chandra • \\ V. James Guillory
}

Published online: 23 September 2008

(C) Springer Science+Business Media, LLC 2008

\begin{abstract}
Taking folic acid daily, before and during early pregnancy, has been proven to reduce neural tube birth defects (NTD). Unfortunately, many women fail to take it daily as recommended. Objectives To assess women's selfreported awareness, knowledge and use of folic acid. Methods Data were obtained by cross-sectional, random digit-dialing, computer-assisted telephone interviews with 250 women in Kansas. Associations were determined by chi-squared analysis. Results Eighty-eight percent of childbearing age women in Kansas have a general awareness of folic acid, $20 \%$ have knowledge that it reduces birth defects, but only $25 \%$ report taking it daily. Awareness was associated with high school or greater education $(P<.0001)$, incomes over $\$ 25,000(P=0.0003)$, being married $(P=0.0035)$, being white $(P=0.0135)$, having health insurance $(P=0.0152)$ and being capable of pregnancy $(P=0.0119)$. Knowledge that folic acid reduces birth defects was associated with being aware of the USPHS recommendation $(P<.0001)$, being capable of pregnancy $(P=0.0043)$, being pregnant $(P=0.0061)$, and being aware of folic acid $(P=0.0379)$. Taking folic acid daily was associated with currently being pregnant
\end{abstract}

G. F. Sharp $(\bowtie) \cdot$ M. L. Hyder · V. J. Guillory

Kansas City University of Medicine and Biosciences, 1750

Independence Ave., Kansas City, MO 64106, USA

e-mail: gsharp@kcumb.edu

L. A. Naylor

School of Public Affairs, University of Baltimore, Baltimore, MD, USA

J. Cai

Kansas City Health Department, Kansas City, MO, USA

P. Chandra

St. Louis University Hospital, St. Louis, MO, USA
$(P=0.0126)$. Conclusions Women less likely to take folic acid on a daily basis were young, non-Caucasians who reported less education, less income and no health insurance. Based upon these data, multi-level education campaigns that specifically target lower-SES women should be considered.

Keywords Folic acid · NTD · Birth defects · Awareness · Knowledge $\cdot$ Random

\section{Background}

Birth defects continue to be a significant cause of infant morbidity and remain the leading cause of infant mortality in the U.S. [1]. Neural tube defects (NTDs), which include anencephaly and spina bifida, affect 1 out of 1,000 pregnancies. Infants born with an NTD are often miscarried, die shortly after birth, or suffer life-long disabilities [2] with individual costs ranging from $\$ 300,000$ [3] to over $\$ 1$ million [4]. Over $70 \%$ of NTDs can be prevented with periconceptual consumption of folic acid [3, 5-7]. However, periconceptual consumption presents a considerable challenge since $50 \%$ of all pregnancies are unplanned [8] and $68 \%$ of young women aged 15 to 24 years report unplanned pregnancies [8].

To achieve the $70 \%$ reduction in NTDs, the U.S. Public Health Service (USPHS) recommends that all childbearing age women capable of pregnancy consume $0.4 \mathrm{mgs}$ of folic acid daily [9], and the U.S. Food and Drug Administration mandates folic acid fortification of enriched cereal grain products [10]. While the prevalence of NTDs has decreased nationally by $26 \%$ since 2000 [11] the expected $70 \%$ reduction has not been achieved [12]. In 2005, awareness of folic acid had risen nationally to $84 \%$, yet knowledge 
that folic acid prevents birth defects was only $19 \%$ [12]. Use of folic acid has increased only modestly: 33\% of women reported taking folic acid daily in 1995 [12] while $40 \%$ reported taking it in 2007 [13].

The aim of this study is to examine awareness, knowledge and use of folic acid among child-bearing age women in Kansas between 18 and 44 years of age. Data analyses will be useful in developing intervention strategies to reduce NTDs in Kansas and other states with similar demographics.

\section{Methods}

Data were obtained by conducting a randomized crosssectional survey using random-digit dialing (RDD) and computer assisted telephone interviewing (CATI) between November 2000 and January 2001. The Institutional Review Board (IRB) for the Kansas City University of Medicine and Biosciences (KCUMB) approved this study prior to data collection. Informed consent was obtained verbally from each participant prior to the telephone interview. The interview assessed respondent perceptions of forty-one questions which were derived from the Behavioral Risk Factor Surveillance Survey (BRFSS) [14], the March of Dimes/Gallup Organization national survey on folic acid [12], and the National Health Interview Survey [15].

There were 6,213 call attempts to get 252 completed calls (4\% response rate) with ten attempts made until disposition for each number. There were $14 \%$ of calls with a non-eligible participant and $4 \%$ refused to participate. Response rate was calculated by the number of completed calls divided by the sum of completed calls plus refusals $(252 / 252+258=49.4 \%)$ with the refusal rate being 1 less the response rate [16].

For this survey, awareness was assessed by respondents having "heard, read, or seen anything" about folic acid, while knowledge indicated respondents knew specifically that folic acid reduces birth defects. A series of three questions were used to determine if a woman consumed folic acid on a daily basis. The first question asked if a woman took any 'vitamin or mineral supplement'. If the response was 'yes', they were asked if 'any of the vitamin or mineral supplements taken included folic acid.' 'Yes' responses were then asked 'how often do you take this vitamin or mineral supplement that contains folic acid' with one of the five choices being 'daily.' Because the recommendation is that women take folic acid daily, the authors considered any response other than 'daily' to be 'not daily' in the analysis.

Data analysis was completed using SAS 9.1. Univariate analyses were conducted using chi-square statistics.
Multivariate logistic and stepwise multiple-logistic regressions were conducted to identify factors that predict awareness, knowledge, and use of folic acid. Factors were considered to be significant at $\alpha<.05$. Women who did not respond or provided 'don't know' responses were considered non-responders and eliminated from the analyses because they were few in number and the characteristics of non-responders were not significantly different from responders (Fisher's Exact $>0.05$ ) [17].

\section{Results}

A total of 250 completed surveys were used in this analysis. Demographic characteristics of study respondents are provided in Table 1. There were seven participants that described themselves as being of Spanish or Hispanic origin. However, because $90.8 \%$ of participants were white, all other races were placed into a 'not white' category to simplify analysis. Almost half of survey respondents were 35 years of age or older, with $37 \%$ between 25 and 34 years, and $13.6 \%<25$ years of age. Most study respondents were white $(90.8 \%)$, had health insurance (86.4\%), an annual household income $\geq \$ 25,000$ $(78.8 \%)$, were married $(76 \%)$, and had some college or were college graduates $(65.6 \%)$. There were $6 \%$ of study respondents that were pregnant at the time of the survey, while $79.6 \%$ had been pregnant before with $95 \%$ of those giving birth to a live child. The characteristics of women in this study reflect the overall demographics of Kansas in 2000 [18].

Table 2 summarizes responses to questions about general awareness of folic acid and being aware of the USPHS recommendation to take folic acid daily. Table 3 shows responses to questions about having the specific knowledge that folic acid prevents birth defects, and Table 4 displays responses of those reporting use of vitamins and folic acid.

Education beyond high school was the factor most strongly associated with having a general awareness of folic acid and being aware of the USPHS recommendation. Having an income $\geq \$ 25,000$, being married, and having health insurance were also significant for both general awareness and awareness of the USPHS recommendation. Being white was strongly associated with being aware of folic acid, but race was not significantly associated with being aware of the USPHS recommendation.

Significant factors associated with the general knowledge there is 'something' a woman can do to prevent birth defects were: education beyond high school, an income $\geq \$ 25,000$, having health insurance, and being aware of folic acid. Being aware of the USPHS recommendation to take folic acid daily was a factor that was significant for having general knowledge, for knowing that taking 
Table 1 Sample characteristics for all women $(n=250)^{\mathrm{a}}$

\begin{tabular}{|c|c|c|}
\hline & $n$ & $\%$ \\
\hline \multicolumn{3}{|l|}{ Age (years) } \\
\hline$<25$ & 34 & 13.6 \\
\hline $25-34$ & 93 & 37.2 \\
\hline $35+$ & 123 & 49.2 \\
\hline \multicolumn{3}{|l|}{ Race } \\
\hline White & 226 & 90.8 \\
\hline Black & 14 & 5.6 \\
\hline Asian, Pacific Islander & 3 & 1.2 \\
\hline American Indian, Alaska native & 5 & 2.0 \\
\hline Other & 1 & 0.4 \\
\hline \multicolumn{3}{|l|}{ Education } \\
\hline$<$ High school & 15 & 6.0 \\
\hline High school graduate & 71 & 28.4 \\
\hline Any college or college graduate & 164 & 65.6 \\
\hline \multicolumn{3}{|l|}{ Marital status } \\
\hline Married & 190 & 76.0 \\
\hline Not married & 60 & 24.0 \\
\hline \multicolumn{3}{|l|}{ Annual household income } \\
\hline$<\$ 15,000$ & 20 & 8.7 \\
\hline$\$ 15,000-\$ 24,999$ & 29 & 12.6 \\
\hline$\$ 25,000-\$ 49,999$ & 85 & 37.0 \\
\hline$\$ 50,000-\$ 69,999$ & 56 & 24.4 \\
\hline$\geq \$ 70,000$ & 40 & 17.4 \\
\hline \multicolumn{3}{|l|}{ Health insurance } \\
\hline Yes & 216 & 86.4 \\
\hline No & 34 & 13.6 \\
\hline \multicolumn{3}{|l|}{ Is capable of pregnancy } \\
\hline Yes & 189 & 75.9 \\
\hline No & 60 & 24.1 \\
\hline \multicolumn{3}{|l|}{ Currently pregnant } \\
\hline Yes & 15 & 6.0 \\
\hline No & 234 & 94.0 \\
\hline
\end{tabular}

${ }^{a}$ Each category may not equal 250 due to non-response

vitamins reduced birth defects, and knowing that specifically taking folic acid reduces birth defects. Other factors significantly associated with specifically knowing that taking folic acid reduces birth defects were: being capable of pregnancy and being pregnant at the time of the survey.

Over half the women who responded to the survey said they take a vitamin or mineral supplement. Of those women that reported taking a vitamin or mineral, 95 (66\%) said the vitamin contained folic acid. For those who knew they were taking folic acid, $63(66 \%)$ stated they took it daily. Thus, of the 250 women surveyed, only $25 \%$ took folic acid daily.

Factors associated with women taking a vitamin or mineral supplement were education, having health insurance, and having the specific knowledge that folic acid prevents birth defects. However, the factors associated with a woman reporting she specifically took a vitamin containing folic acid were having a general awareness of folic acid and being aware of the USPHS recommendation. The only factor significantly associated with taking folic acid daily was being pregnant. In this survey, 15 women reported being pregnant, and all of them reported taking folic acid daily.

The single factor logistic regression showed that women capable of pregnancy and those with insurance were almost three times more likely to be aware of folic acid (O.R. 2.76, 95\% CI 1.22-6.24; and, 2.99, 95\% CI 1.19-7.46 respectively). Women with incomes $\geq \$ 25,000$ were more than five times as likely to be aware of folic acid (O.R. 5.44, 95\% CI 1.19-7.46), while women with an education beyond high school were approximately nine times more likely to be aware of folic acid (O.R. 8.83, 95\% CI 2.9126.78). Women that were capable of pregnancy were almost four times more likely to know that folic acid reduced birth defects (O.R. 3.85, 95\% CI 1.44-10.24).

With all factors included in a multiple logistic regression analysis, age was a significant factor $(P=0.0254)$ that affected 'lack of awareness.' Women aged $35+$ were four times less likely to be aware of folic acid (OR 4.15; CI 1.19-14.48) compared to women 25 to 34 years of age. This was true even though the results shown in Table 2 for the individual factors of awareness shows that age was not a significant factor by itself. Results of the multiple regression analysis also showed that women with less than a high school education were five times less likely to be aware of folic acid (OR 5.23; CI 1.05-26.20).

\section{Discussion}

In this 2001 cross sectional study of Kansas women, 88\% reported being aware of folic acid compared to $79 \%$ nationally in 2003 [19] while 55\% reported being aware of the USPHS recommendation compared to $22 \%$ nationally in 1997 [20]. With only $25 \%$ of women in this study taking any amount of folic acid daily, there appears to be a significant gap between awareness, knowledge and actual use of folic acid in Kansas. It is interesting to note that there is very little difference in daily folic acid use between the overall sample of women (25\%) and only those capable of pregnancy $(27 \%)$. The Healthy People 2010 recommendation is for $80 \%$ of all childbearing age women to take the recommended amount of folic acid on a daily basis.

These results confirm previous studies [13, 20-33] that women most likely to be aware of folic acid were married, white, with higher incomes and health insurance. The only factors that actually predict taking folic acid were being aware of folic acid and being aware of the USPHS 
Table 2 Awareness by demographic characteristics

\begin{tabular}{|c|c|c|c|c|c|c|}
\hline \multirow[t]{2}{*}{ Characteristic } & \multicolumn{3}{|c|}{ Aware of folic $\operatorname{acid}^{\mathrm{a}}(n=250)$} & \multicolumn{3}{|c|}{ Aware of USPHS recommendation for folic acid ${ }^{\mathrm{b}}(n=250)$} \\
\hline & Aware $\%$ & Not aware $\%$ & $\chi^{2} P$-value & Aware \% & Not Aware \% & $\chi^{2} P$-value \\
\hline \multicolumn{7}{|l|}{ Age } \\
\hline 18-24 years & 88.2 & 11.8 & 0.1545 & 52.9 & 47.1 & 0.5008 \\
\hline $25-34$ years & 93.6 & 6.5 & & 60.2 & 39.8 & \\
\hline $35+$ years & 85.1 & 14.9 & & 52.5 & 47.5 & \\
\hline \multicolumn{7}{|l|}{ Race } \\
\hline White & 90.2 & 9.8 & 0.0135 & 57.3 & 42.7 & 0.0942 \\
\hline Not White & 72.7 & 27.3 & & 39.1 & 60.9 & \\
\hline \multicolumn{7}{|l|}{ Education } \\
\hline$<$ High school & 53.3 & 46.7 & $<.0001$ & 26.7 & 73.3 & 0.0208 \\
\hline High school or college & 91.0 & 9.0 & & 57.3 & 42.7 & \\
\hline \multicolumn{7}{|l|}{ Marital status } \\
\hline Married & 92.0 & 8.0 & 0.0035 & 61.4 & 38.6 & 0.0008 \\
\hline Not married & 78.3 & 21.7 & & 36.7 & 63.3 & \\
\hline \multicolumn{7}{|l|}{ Income } \\
\hline$<\$ 25,000$ & 75.5 & 24.5 & 0.0003 & 36.7 & 63.3 & 0.0029 \\
\hline$\geq \$ 25,000$ & 93.3 & 6.7 & & 60.6 & 39.4 & \\
\hline \multicolumn{7}{|l|}{ Health insurance } \\
\hline Yes & 90.7 & 9.4 & 0.0152 & 58.1 & 41.9 & 0.0300 \\
\hline No & 76.5 & 23.5 & & 38.2 & 61.8 & \\
\hline \multicolumn{7}{|l|}{ Capable of pregnancy } \\
\hline Is capable & 91.5 & 8.5 & 0.0119 & 60.6 & 39.4 & 0.0036 \\
\hline Is not capable & 79.7 & 20.3 & & 39.3 & 60.7 & \\
\hline \multicolumn{7}{|l|}{ Pregnancy status } \\
\hline Pregnant & 93.3 & 6.7 & 0.5850 & 80.0 & 20.0 & 0.0501 \\
\hline Not pregnant & 88.8 & 11.2 & & 54.1 & 45.9 & \\
\hline \multicolumn{7}{|l|}{ Aware of folic acid } \\
\hline Yes aware & & & & 62.1 & 37.9 & $<.0001$ \\
\hline Not aware & & & & 7.1 & 92.9 & \\
\hline
\end{tabular}

${ }^{a}$ Have you ever heard, read or seen anything about folic acid? (220 yes)

${ }^{\mathrm{b}}$ Have you heard the USPHS recommendation of 400 micrograms of folic acid a day? (138 yes)

Reference Groups: 1. Age 25-34; 2. Race (White); 3. Education ( $>$ HS); 4. Married; 5. Income ( $>25 \mathrm{~K})$; 6. Insurance; 7. Capable of pregnancy; 8. Pregnant; 9. Aware of Folic Acid

recommendation to take folic acid daily. This highlights the critical importance of large scale, continuous education efforts to increase awareness. For women in this study, once they become pregnant, or intend to become pregnant, they have the knowledge that folic acid prevents birth defects. Unfortunately, for some women, this knowledge comes too late in the pregnancy to prevent an NTD.

The major strength of this study is that it was a randomized cross-sectional survey. A second strength is that it looks at women in a central mid-west state (Kansas). The demographics in Kansas are different than most other states where folic acid studies have been conducted [13, 20-33]. The lack of racial diversity in Kansas should simplify the development of educational campaigns to promote the importance of folic acid throughout Kansas.

The survey instrument has strong validity. All questions used in this analysis were from the BRFSS survey developed by the Centers for Disease Control and Prevention (CDC) with rigorous validation techniques. Even though the survey instrument was not re-validated, because BRFSS responses are used at the national and state level for prevalence rates, the authors feel the analysis has strong validity.

There are a few notable limitations of this study. One limitation is that there was no information on the amount of folic acid contained in the vitamin or mineral 
Table 3 Knowledge that a woman can reduce birth defects by demographic characteristics

\begin{tabular}{|c|c|c|c|c|c|c|c|c|c|}
\hline \multirow[t]{2}{*}{ Characteristic } & \multicolumn{3}{|c|}{ Do something $^{\mathrm{a}}(n=250)$} & \multicolumn{3}{|c|}{ Take vitamins $^{\mathrm{b}}(n=65)$} & \multicolumn{3}{|c|}{ Take folic $\operatorname{acid}^{\mathrm{c}}(n=51)$} \\
\hline & Yes $\%$ & No $\%$ & $\overline{\chi^{2} P \text {-value }}$ & Yes $\%$ & No $\%$ & $\overline{\chi^{2} P \text {-value }}$ & Yes $\%$ & No $\%$ & $\chi^{2} P$-value \\
\hline \multicolumn{10}{|l|}{ Age } \\
\hline 18-24 years & 90.6 & 9.4 & 0.5381 & 37.9 & 62.1 & 0.2052 & 34.5 & 65.5 & 0.2265 \\
\hline $25-34$ years & 89.1 & 10.9 & & 32.9 & 67.1 & & 23.2 & 76.8 & \\
\hline $35+$ years & 93.4 & 6.6 & & 23.9 & 76.1 & & 19.5 & 80.5 & \\
\hline \multicolumn{10}{|l|}{ Race } \\
\hline White & 91.9 & 8.1 & 0.3778 & 28.4 & 71.6 & 0.4404 & 24.5 & 75.5 & 0.0561 \\
\hline Not White & 86.4 & 13.6 & & 36.8 & 63.2 & & 5.3 & 94.7 & \\
\hline \multicolumn{10}{|l|}{ Education } \\
\hline$<$ High school & 60.0 & 40.0 & $<.0001$ & 33.3 & 66.7 & 0.7709 & 22.2 & 77.8 & 0.9682 \\
\hline High school or college & 93.5 & 6.5 & & 28.8 & 71.2 & & 22.8 & 77.2 & \\
\hline \multicolumn{10}{|l|}{ Marital status } \\
\hline Married & 92.0 & 8.0 & 0.5808 & 27.9 & 72.1 & 0.5052 & 22.1 & 77.9 & 0.6614 \\
\hline Not married & 89.7 & 10.3 & & 32.7 & 67.3 & & 25.0 & 75.0 & \\
\hline \multicolumn{10}{|l|}{ Income } \\
\hline$<\$ 25,000$ & 79.2 & 20.8 & 0.0010 & 31.6 & 68.4 & 0.7686 & 18.4 & 81.6 & 0.4747 \\
\hline$\geq \$ 25,000$ & 94.4 & 5.6 & & 29.2 & 70.8 & & 23.8 & 76.2 & \\
\hline \multicolumn{10}{|l|}{ Health insurance } \\
\hline Yes & 93.4 & 6.6 & 0.0070 & 28.4 & 71.6 & 0.5983 & 23.9 & 76.1 & 0.2933 \\
\hline No & 79.4 & 20.6 & & 33.3 & 66.7 & & 14.8 & 85.2 & \\
\hline \multicolumn{10}{|l|}{ Capable of pregnancy } \\
\hline Is capable & 90.8 & 9.2 & 0.5442 & 29.8 & 70.2 & 0.6708 & 27.4 & 72.6 & 0.0043 \\
\hline Is not capable & 93.3 & 6.7 & & 26.8 & 73.2 & & 8.9 & 91.1 & \\
\hline \multicolumn{10}{|l|}{ Pregnancy status } \\
\hline Pregnant & 86.7 & 13.3 & 0.5005 & 30.8 & 69.2 & 0.8945 & 53.9 & 46.2 & 0.0061 \\
\hline Not pregnant & 91.7 & 8.3 & & 29.1 & 71.0 & & 21.0 & 79.1 & \\
\hline \multicolumn{10}{|l|}{ Aware of folic acid } \\
\hline Yes aware & 93.5 & 6.5 & 0.0010 & 30.2 & 69.8 & 0.2846 & 24.8 & 75.3 & 0.0379 \\
\hline Not aware & 75.0 & 25.0 & & 19.1 & 81.0 & & 4.8 & 95.2 & \\
\hline \multicolumn{10}{|c|}{ Aware of USPHS recommendation } \\
\hline Yes aware & 97.8 & 2.2 & $<.0001$ & 34.8 & 65.2 & 0.0211 & 33.3 & 66.7 & $<.0001$ \\
\hline Not aware & 83.0 & 17.0 & & 20.5 & 79.6 & & 6.8 & 93.2 & \\
\hline
\end{tabular}

${ }^{a}$ From what you know, is there anything a woman can do to reduce her risk of having a baby with birth defects? (224 yes)

b Specifically mentioned taking vitamins when asked "What can a woman do to reduce the risk of birth defects?" $(n=65)$

c Specifically mentioned taking folic acid when asked "What can a woman do to reduce the risk of birth defects?" $(n=51)$

Reference groups: 1. Age 25-34; 2. Race (White); 3. Education (>HS); 4. Married; 5. Income ( $>$ 25 K); 6. Insurance; 7. Capable of pregnancy; 8. Pregnant; 9. Aware of folic acid; 10. Aware of USPHS recommendation

supplement taken. Thus, even though a woman reports using folic acid daily, it is impossible to determine if the vitamin or supplement contained the recommended 400 micrograms. Another limitation is that only one delivery method of folic acid was assessed-vitamins and supplements taken orally. To get a complete picture, respondents could have been asked about dietary intake of foods containing folic acid. An added limitation is that women $18-24$ years of age $(n=34)$ were under-represented, while women 35-44 years may have been over- represented $(n=123)$. By not including women younger than 18 years, an important group may have been left out that could greatly benefit from taking folic acid to prevent adverse birth outcomes.

There may also be a generation difference in responses. The USPHS recommendation was not issued until 1992 and widespread national support was not given until 1998. Thus, younger women may have known about folic acid from the time they were of reproductive age, while older women may not have known of the recommendation. 


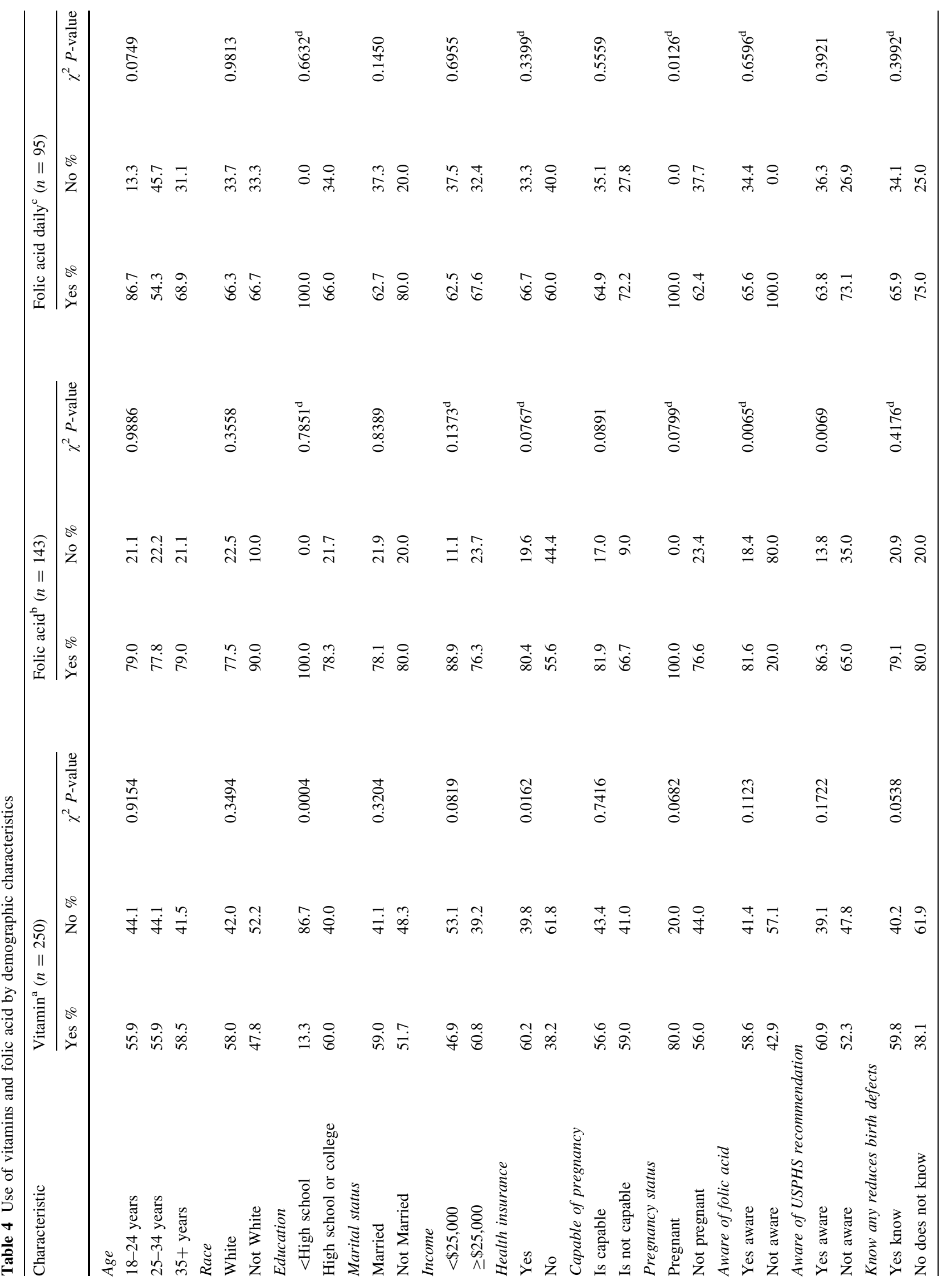




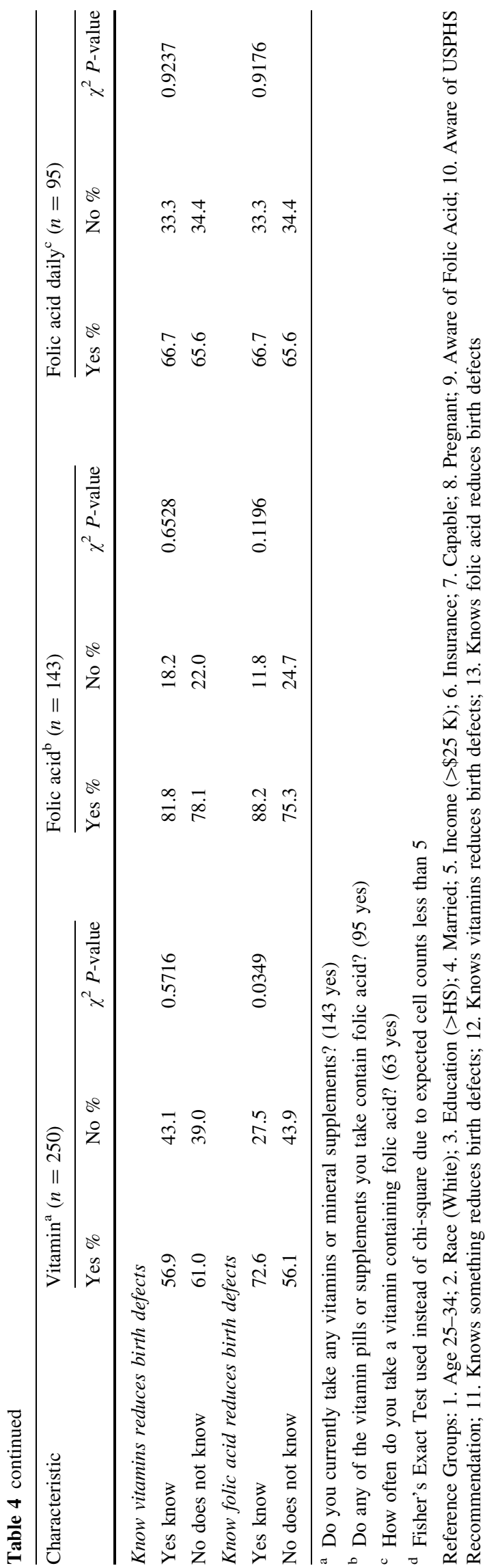

Another limitation is that recall bias may have been introduced into the analysis because all responses were self-reported.

\section{Conclusion}

Many women are aware of folic acid, but fewer know about its role in preventing NTDs, and even less take it daily as recommended. In order to reduce NTDs, multi-level education strategies that target lower SES women must be developed and delivered continuously. It is critical that women recognize the importance of folic acid and take it daily as recommended to reduce the number of NTDs.

Acknowledgements This study received funding from the Kansas City University of Medicine and Biosciences. The authors gratefully acknowledge the approval from the Kansas and Western Missouri Chapter of the March of Dimes for the project, and access to their Gallup Poll survey results. The authors wish to express their appreciation for the advice and critique of faculty members at the University of Kansas School of Medicine, specifically Michael Fox, $\mathrm{ScD}$, Norge Jerome, $\mathrm{PhD}$, and Matthew $\mathrm{S}$. Mayo, $\mathrm{PhD}$, who provided statistical critique, and the March of Dimes. The researchers are thankful for the information shared by the Kansas Department of Health and Environment, Center for Health and Environmental Statistics, Office of Health Care Information, the Bureau of Health Promotion, the Behavioral Risk Factor Surveillance System, and the Bureau for Children, Youth and Families. The authors acknowledge the significant contribution of Cathy Carroll, $\mathrm{PhD}$, for her critical editorial review and comments. All authors acknowledge they have no financial or other competing interests that may have influenced or created bias in this work.

\section{References}

1. Petrini, J., Damus, K., Russell, R., Poschman, K., Davidoff, M. J., \& Mattison, D. (2002). Contribution of birth defects to infant mortality in the United States. Teratology, 66(Suppl 1), S3-S6. doi:10.1002/tera.90002.

2. Mitchell, L. E., Adzick, N. S., Melchionne, J., Pasquariello, P. S., Sutton, L. N., \& Whitehead, A. S. (2004). Spina bifida. Lancet, 364(9448), 1885-1895. doi:10.1016/S0140-6736(04)17445-X.

3. CDC. (1995). Economic costs of birth defects and cerebral palsy-United States, 1992. Morbidity and Mortality Weekly Report, 1995(14), 493-505.

4. Wasserman, C. R., Shaw, G. M., Selvin, S., Gould, J. B., \& Syme, S. L. (1998). Socioeconomic status, neighborhood social conditions, and neural tube defects. American Journal of Public Health, 88(11), 1674-1680.

5. Czeizel, A. E., \& Dudas, I. (1992). Prevention of the first occurrence of neural-tube defects by periconceptional vitamin supplementation. The New England Journal of Medicine, $327(26), 1832-1835$.

6. Group, M. V. S. R. (1991). Prevention of neural tube defects: Results of the MRC Vitamin Study. Lancet, 338, 132-137.

7. Shaw, G. M., Schaffer, D., Velie, E. M., Morland, K., \& Harris, J. A. (1995). Periconceptional vitamin use, dietary folate, and the occurrence of neural tube defects. Epidemiology (Cambridge, Mass), 6(3), 219-226. doi:10.1097/00001648-199505000-00005. 
8. Henshaw, S. K. (1998). Unintended pregnancy in the United States. Family Planning Perspectives, 30(1), 24-29. doi:10.2307/ 2991522.

9. CDC. (1992). Recommendations for the use of folic acid to reduce the number of cases of spina bifida and other neural tube defects. Morbidity and Mortality Weekly Report 1992, 41(RR-14), 001.

10. Administration USFaD. (1996). Folic acid fortification, FDA fact sheet. February 29.

11. CDC. (2004). Spina bifida anencephaly before and after folic acid mandate-United States 1995-1996 and 1999-2000. Morbidity and Mortality Weekly Report 1995-1996 and 1999-2000, 53, 362-365.

12. Green-Raleigh, K., Carter, H., Mulinare, J., Prue, C., \& Petrini, J. (2006). Trends in folic acid awareness and behavior in the United States: The Gallup Organization for the March of Dimes Foundation Surveys, 1995-2005. Maternal and Child Health Journal, 10, S177-S182. doi:10.1007/s10995-006-0104-0.

13. Herndorf, A. M., Haydu, S. C., \& Takahashi, E. R. (2007). Trends in folic acid supplement intake among women of reproductive age in California, 2002-2006. Morbidity and Mortality Weekly Report, 56(42), 1106-1109.

14. Centers for Disease Control. (1999) Behavioral risk factor surveillance system questionnaire, module 13: Folic acid, p. 81. http://www.cdc.gov/brfss/questionnaires/pdf-ques/99brfss.pdf. Accessed 14 August 2000.

15. Centers for Disease Control and Prevention. National Center for Health Statistics. (1997). National Health Interview Survey. ftp:// ftp.cdc.gov/pub/Health_Statistics/NCHS/Survey_Questionnaires/ NHIS/1997/frmanual.pdf. Accessed 14 August 2000.

16. Southwest Missouri State University, Department of Sociology \& Anthropology, Springfield, MO. January 16, 2001.

17. Agresti, A. (2002). Categorical data analysis (2nd ed., p. 476).

18. U.S. Census Bureau. (2000). American fact finder, Kansas. http://factfinder.census.gov. Accessed 22 January 2008.

19. March of Dimes. (2003). Why don't women take folic acid? Forgetfulness and Denial, latest survey finds. March of Dimes website. http://www.charitywire.com/charity91/04217.html. Accessed 13 December 2007.

20. Anonymous. (1997). Knowledge and use of folic acid by US women. Nutrition Research Newsletter.

21. Serbanescu, F., Rochat, R., Floyd, V., \& Toomey, K. (1996). Knowledge, use of multivitamins containing folic acid among reproductive-aged women, Georgia, 1995. Morbidity and Mortality Weekly Report, 1996(45), 793-795.

22. Petrini, J., Damus, K., Johnston, R., \& Mattison, D. (1999). Knowledge and use of folic acid by women of childbearing ageUnited States 1995 and 1998. Morbidity and Mortality Weekly Report, 48(16), 325-327.
23. Reeves, M., Rafferty, A., Simmeron, J., \& Bach, J. (1998). Knowledge, use of folic acid among women of reproductive age, Michigan. Morbidity and Mortality Weekly Report, 2001(50), 185-189.

24. Benjamin-Garner, R., Oakes, J., Meischke, H., Meshack, A., Stone, E., Zapka, J., et al. (2002). Sociodemographic differences in exposure to health information. Ethnicity and Disease, 12, 124-134. (Winter 2002).

25. Canfield, M., Anderson, J., Waller, K., Palmer, S., \& Kaye, C. (2000-2001). Folic acid awareness and use among women with a history of neural tube defect pregnancy-Texas, 2000-2001. Morbidity and Mortality Weekly Report, 51, 16-19.

26. Feldkamp, M., Friedrichs, M., \& Marti, K. (2002). Folic acid awareness, knowledge, and consumption among women of childbearing age in Utah, 1998-2000. American Journal of Medical Genetics, 107(1), 67-69. doi:10.1002/ajmg.10097.

27. Meyer, R., \& Siega-Riz, A. (2002). Sociodemographic patterns in spina bifida birth prevalence trends: North Carolina, 1995-1999. Morbidity and Mortality Weekly Report, 51, 12-15.

28. Chacko, M. R., Anding, R., Kozinetz, C. A., Grover, J. L., \& Smith, P. B. (2003). Neural tube defects: Knowledge and preconceptional prevention practices in minority young women. Pediatrics, 112(3 Pt 1), 536-542. doi:10.1542/peds.112.3.536.

29. Cleves, M. A., Hobbs, C. A., Collins, H. B., Andrews, N., Smith, L. N., \& Robbins, J. M. (2004). Folic acid use by women receiving routine gynecologic care. Obstetrics and Gynecology, 103(4), 746-753.

30. de Jong-Van den Berg, L. T., Hernandez-Diaz, S., Werler, M. M., Louik, C., \& Mitchell, A. A. (2005). Trends and predictors of folic acid awareness and periconceptional use in pregnant women. American Journal of Obstetrics and Gynecology, 192(1), 121-128. doi:10.1016/j.ajog.2004.05.085.

31. Goldberg, B. B., Alvarado, S., Chavez, C., Chen, B. H., Dick, L. M., Felix, R. J., et al. (2006). Prevalence of periconceptional folic acid use and perceived barriers to the postgestation continuance of supplemental folic acid: Survey results from a Teratogen Information Service. Birth Defects Research. Part A, Clinical and Molecular Teratology, 76(3), 193-199. doi:10.1002/bdra.20239.

32. Robbins, J. M., Hopkins, S. E., Mosley, B. S., Casey, P. H., Cleves, M. A., \& Hobbs, C. A. (2006). Awareness and use of folic acid among women in the lower Mississippi Delta. The Journal of Rural Health, 22(3), 196-203. doi:10.1111/j.17480361.2006.00032.x.

33. Lindsey, L., Petrini, J., Carter, H., Prue, C., \& Mulinare, J. (2005). Use of dietary supplements containing folic acid among women of childbearing age-United States, 2005. Morbidity and Mortality Weekly Report, 54(38), 955-958. 
Copyright of Maternal \& Child Health Journal is the property of Springer Science \& Business Media B.V. and its content may not be copied or emailed to multiple sites or posted to a listserv without the copyright holder's express written permission. However, users may print, download, or email articles for individual use. 